\title{
Ockham on the (In)fallibility of Intuitive Cognition
}

\author{
Lorenz Demey
}

\begin{abstract}
The main purpose of this paper is to reassess the debate between Boehner and Karger about Ockham's views on the infallibility of intuitive cognition, and to present a new account of infallible intuitive cognition. After a detailed overview of Ockham's theory of intuitive and abstractive cognition, the Boehner/Karger debate is examined. At the center of this debate are two conflicting interpretations of a certain passage in Ockham's writings. It is shown that neither of these interpretations is ultimately successful. Next, a third interpretation is introduced and shown to be superior to the previous two. This new interpretation leads to a refutation of one of Karger's main arguments against Boehner's theory of the infallibility of intuitive cognition. Finally, a distinction between weak and strong infallibility is introduced, and it is argued that intuitive cognition is always weakly infallible, and often (but not always) also strongly infallible.
\end{abstract}

\section{Ockham über die (In)fallibilität der Intuitiven Kognition (abstract in German)}

Das Ziel dieses Artikels ist es, die Debatte über Ockhams Ansichten zur Infallibilität intuitiver Kognitions zwischen Boehner und Karger neu zu beurteilen und eine neue Theorie der infallibelen intuitiven Kognition zu präsentieren. Nach einem detaillierten Überblick über Ockhams Theorie der intuitiven und abstraktiven Kognition wird die Boehner/Karger Debatte untersucht. Im Mittelpunkt dieser Debatte stehen zwei unterschiedliche Interpretationen einer bestimmten Passage in Ockham's Schriften. Es wird gezeigt, dass keine dieser Interpretationen überzeugend ist. Danach wird eine dritte Interpretation gegeben und gezeigt, dass diese Interpretation besser ist als ihre Rivalen. Die neue Interpretation führt zur Widerlegung von Kargers Hauptargument gegen Boehners Theory der Infallibilität der intuitiven Kognition. Schließlich wird eine Unterscheidung zwischen schwacher und starker Infallibilität eingeführt und es wird argumentiert, dass intuitive Kognition immer schwach infallibel ist und oft (aber nicht immer) stark infallibel.

\section{Introduction}

Ockham's theory of intuitive and abstractive cognition forms the very core of his epistemology. Many central features of this theory have, however, also been the subject of much debate amongst Ockham scholars. Since Philotheus Boehner's influential account in (Boehner 1943), a quasigeneral consensus has started to develop that intuitive cognition is infallible. Elizabeth Karger, however, has argued that Boehner's claims about the infallibility of intuitive cognition are based on a misunderstanding of one of Ockham's texts, and that according to Ockham's 'real' theory, intuitive cognition is fallible (Karger 1999).

The main purpose of this paper is to reassess the Boehner/Karger debate, and to present a new theory of the infallibility of intuitive cognition. Sections 2 and 3 provide an overview of Ockham's theory of intuitive and abstractive cognition, extensively illustrated with quotations from Ockham's original writings. ${ }^{1}$ In Section 4, I turn to the Boehner/Karger debate: I will consecutively discuss

1 The works by Ockham that will be used are the Prologus of his Ordinatio (abbreviated as 'Ord. Prol.'), his Reportatio (abbreviated as 'Rep.'), and his Quodlibeta Septem (abbreviated as 'Quod.'). These can be found in volumes I, V and IX of his Opera Theologica (abbreviated as 'OTh'). All English translations are my own. 
Boehner's interpretation of one of Ockham's texts, Karger's reconstruction of Boehner's interpretation, and finally, Karger's own interpretation. In Section 5, it is argued that neither Boehner's nor Karger's interpretation is ultimately successful. I then propose a third interpretation and argue for its correctness. I also explain how this third interpretation leads to a refutation of one of Karger's arguments against Boehner's theory of the infallibility of intuitive cognition. Finally, I distinguish between a weak and a strong sense of the term 'infallible' (based on whether the intuitive cognition causes a false judgment, or merely co-occurs with it), and argue that intuitive cognition is always weakly infallible, and often (although not always) also strongly infallible.

\section{Ockham's Theory of Intuitive and Abstractive Cognition}

In this section, I will provide a general outline of Ockham's theory of natural intuitive and abstractive cognition, focusing on those aspects that will turn out to be central in the Boehner/Karger debate. ${ }^{2}$ This overview of Ockham's theory of naturally caused cognition will in the next section be supplemented with an outline of his theory of supernaturally (divinely) caused cognition.

We begin this outline with a preliminary remark regarding Ockham's distinction between complex and non-complex cognitions. These two kinds of cognitions are distinguished by their contents: non-complex cognitions have non-propositional contents, whereas complex cognitions have propositions or demonstrations (which have 'internal structure') as content; "we apprehend not only that which is non-complex, but also propositions and demonstrations". ${ }^{3}$ The complex cognition of a proposition $\mathrm{P}$ is sometimes also called a 'judgment that $\mathrm{P}$ ' or 'assent to $\mathrm{P}$ '.

According to Ockham, intuitive and abstractive cognitions are non-complex cognitions: "our intellect, even in this life, can have two specifically distinct non-complex cognitions of the same thing under the same aspect. One of them may be called 'intuitive', the other 'abstractive"' 5 . An intuitive cognition of an object $\mathrm{A}$ is caused by that object itself. Thus, speaking naturally, ${ }^{6}$ an intuitive cognition of $\mathrm{A}$ implies that A exists: if A did not exist, the intuitive cognition of A could not have come into being. "[N]aturally, there cannot be an intuitive cognition without the existence of the thing, which is truly the efficient cause of the intuitive cognition". ${ }^{7}$ Furthermore, it is exactly because of this causal relation that the intuitive cognition of $\mathrm{A}$ is a cognition of $A$ and not of some other thing (which perhaps looks exactly like A): "an intuitive cognition is a proper cognition of a singular thing not because of its greater likeness to one thing than to another, but because it is naturally caused by the one thing and not by the other, and cannot be caused by the other". 8

To understand the main difference between intuitive and abstractive cognition, we first need to introduce the notion of evident cognition. Ockham defines evident cognition as "knowledge of a true proposition which is of a nature to be sufficiently caused, immediately or mediately, by the non-complex cognition of its terms". 9 Evident cognitions are thus complex (their contents are

2 A question that will not be discussed in this paper is, for example, whether someone can have intuitive cognition of her own mental (intellectual) acts. Concerning this question, see (Quod. I, q. 14, OTh IX, 78-82).

3 "apprehendimus non tantum incomplexa sed etiam propositiones et demonstrationes" (Ord. Prol., q. 1, OTh I, 16).

4 It should be stressed that this claim is only valid within one particular 'classification' of the various types of cognitions. Ockham also has an alternative classification, according to which all non-intuitive cognitions (including the complex ones) are called 'abstractive'. This alternative classification will be discussed at the end of this section.

5 "intellectus noster etiam pro statu isto respectu eiusdem obiecti sub eadem ratione potest habere duas notitias incomplexas specie distinctas, quarum una potest dici intuitiva et alia abstractiva” (Ord. Prol., q. 1, OTh I, 15).

6 I.e. excluding supernatural (divine) events, which will be discussed in the next section.

7 "naturaliter notitia intuitiva non possit esse sine exsistentia rei, quae est vere causa efficiens notitiae intuitivae" (Ord. Prol., q. 1, OTh I, 38).

8 "intuitiva est propria cognitio singularis, non propter maiorem assimilationem uni quam alteri, sed quia naturaliter ab uno et non ab altero causatur, nec potest ab altero causari” (Quod. I, q. 13, OTh IX, 76).

9 "notitia evidens est cognitio alicuius veri complexi, ex notitia terminorum incomplexa immediate vel mediate nata sufficienter causari” (Ord. Prol., q. 1, OTh I, 5). 
propositions), and hence a particular kind of judgment/assent. Furthermore, evident cognition is infallible: if one has an evident cognition of a proposition, it follows immediately that that proposition has to be true (because, by definition, evident cognition is knowledge of true propositions).

The main difference between intuitive and abstractive cognition is that an intuitive cognition of an object A can cause an evident cognition of a (present-tensed) contingent proposition about A, whereas an abstractive cognition of A cannot: "every non-complex cognition of one or more terms or things is an intuitive cognition, if it enables us to know a contingent truth evidently, especially about the present $[. .$.$] through abstractive cognition no contingent truth, especially none about the$ present, can be known evidently". ${ }^{10}$ For example, if someone has an intuitive cognition of A, she can know evidently the (present-tensed) contingent proposition that A exists; or "if someone intuitively sees Socrates and the whiteness that exists in Socrates, then she can know evidently [the present-tensed contingent proposition] that Socrates is white". ${ }^{11}$

Ockham states that "as soon as there is an intuitive cognition of a thing, I have at the same time an abstractive cognition of this same thing". ${ }^{12}$ The abstractive cognition is ontologically dependent on the intuitive cognition: "an abstractive cognition of a singular presupposes an intuitive [cognition] with respect to the same object, and not vice versa" ${ }^{13}$ In other words, speaking naturally (recall Footnote 6), the abstractive cognition of a thing cannot exist without there first existing an intuitive cognition of that thing. Furthermore, the intuitive and abstractive cognitions do not just cooccur; rather, the intuitive cognition causes the abstractive cognition: "the effective cause of the intuitive cognition [of a thing] is the cognized thing itself, but the effective cause of the abstractive cognition is the intuitive cognition itself or a habit that inclines to that abstractive cognition". ${ }^{14}$ (The last part of this quotation - about the habit - is related to Ockham's account of memory, which is not directly relevant to the Boehner/Karger debate, and which will therefore not be discussed here. $)^{15}$

Scheme 1 summarizes the presentation of Ockham's theory of (naturally caused) intuitive and abstractive cognition (arrows represent causal relations).

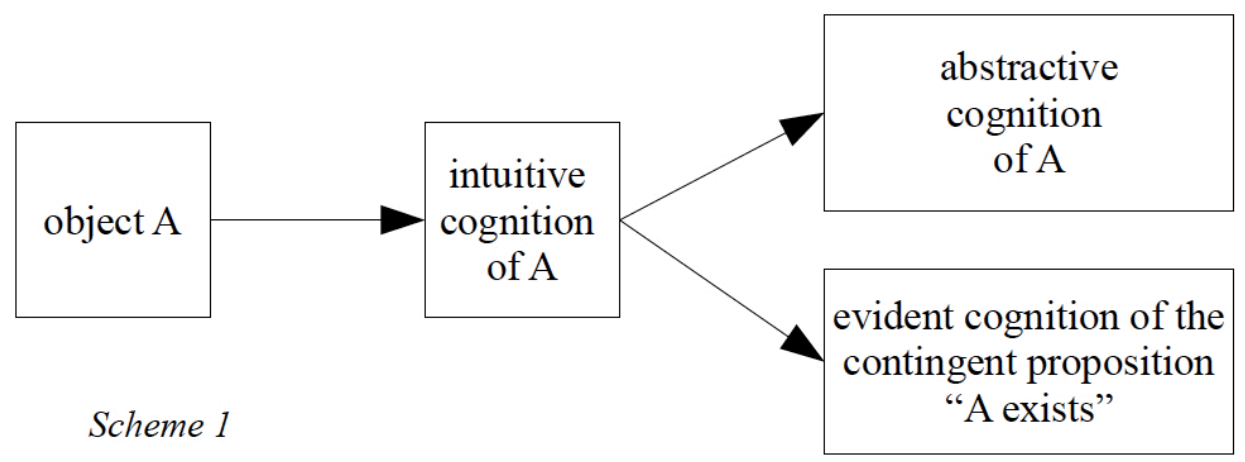

10 "universaliter omnis notitia incomplexa termini vel terminorum, seu rei vel rerum, virtute cuius potest evidenter cognosci aliqua veritas contingens, maxime de praesenti, est notitia intuitiva [...] per notitiam abstractivam nulla veritas contingens, maxime de praesenti, potest evidenter cognosci” (Ord. Prol., q. 1, OTh I, 31-32).

11 "si aliquis videat intuitive Sortem et albedinem existentem in Sorte, potest evidenter scire quod Sortes est albus" (Ord. Prol., q. 1, OTh I, 6).

12 "stante cognitione intuitiva alicuius rei, habeo simul et semel cognitionem abstractivam eiusdem rei" (Rep., q. 1213, OTh V, 261).

13 "cognitio singularis abstractiva praesupponit intuitivam respectu eiusdem obiecti et non econverso" (Quod. I, q. 13, OTh IX, 73).

14 "causa effectiva notitiae intuitivae est ipsa res nota, causa autem effectiva notitiae abstractivae est ipsamet notitia intuitiva vel aliquis habitus inclinans ad notitiam abstractivam" (Ord. Prol., q. 1, OTh I, 61).

15 Ockham actually had two theories of memory. It is very likely, however, that he discarded one theory in favour of the other (Adams 1987, 518). 
I conclude this general overview of Ockham's theory of (naturally caused) cognition by pointing out a terminological distinction which will become relevant later in the paper. So far, I have said that intuitive and abstractive cognitions are both non-complex, i.e. not of propositions (or of demonstrations). However, Ockham uses the term 'abstractive cognition' also in a broader sense. ${ }^{16}$ In this broad sense, every cognition which is not intuitive (including all complex cognitions of propositions) is called 'abstractive'. Ockham introduces this second, 'broad' sense of 'abstractive cognition' as follows:

$[\mathrm{N}]$ either the formation of the complex nor the act of assenting to it is an intuitive cognition. For both of these are complex cognitions, and intuitive cognition is noncomplex. If these two [terms], 'abstractive' and 'intuitive', were to divide all cognition, complex as well as non-complex, then these cognitions [i.e. the formation of the complex and the act of assenting to it] would be called abstractive cognitions, just as every [other] complex cognition would be called abstractive. ${ }^{17}$

\section{Intuitive Cognition of Non-Existent Objects}

In the previous section I presented Ockham's theory of naturally caused intuitive and abstractive cognition, without taking into consideration possible supernatural (divine) causal acts. We have seen that, within this natural framework, an intuitive cognition of an object A can cause an evident cognition of the proposition that A exists, and is thus possible only if A really exists. This is, however, no longer the case when supernatural (divine) causal acts are taken into consideration: "by God's power there can be an intuitive cognition of an object that does not exist". ${ }^{18}$ In this section, I present Ockham's proofs for this claim and discuss its consequences regarding the evident cognition which is caused by such an intuitive cognition of a non-existent object.

Ockham's first proof relies on the principle that everything which God can produce using a secondary cause, he can also produce directly, in the absence of that secondary cause. When someone has a (naturally caused) intuitive cognition of an object A, God can be said to have caused this intuitive cognition indirectly, using the cognized object A itself as a secondary cause. Therefore, God can also produce this intuitive cognition of A directly, in the absence of the secondary cause, i.e. in the absence of A. ${ }^{19}$

Ockham's second proof is based on the principle that when two absolute things differ in place and subject, it is possible for God to destroy one object without destroying the other one. An object $\mathrm{A}$ and an intuitive cognition of $\mathrm{A}$ are indeed two absolute things, differing in place and subject. Therefore, it is possible for God to destroy A while not destroying the intuitive cognition of A. For example, "if I intuitively see a star existing in the sky, this intuitive vision, whether it is sensory or intellective, differs from the seen object [i.e. from the star] in both place and subject; consequently, this vision can remain while the star is destroyed". ${ }^{20}$ Quite obviously, after God has destroyed the

16 Recall Footnote 4.

17 "nec formatio complexi nec actus assentiendi complexo est cognitio intuitiva. Quia utraque cognitio est cognitio complexa, et cognitio intuitiva est cognitio incomplexa. Et tunc, si ista duo, abstractivum et intuitivum, dividant omnem cognitionem tam complexam quam incomplexam, tunc istae cognitiones dicerentur cognitiones abstractivae; et omnis cognitio complexa [diceretur] abstractiva" (Rep., q. 12-13, OTh V, 257).

18 "cognitio intuitiva potest esse per potentiam divinam de obiecto non existente" (Quod. VI, q. 6, OTh IX, 604).

19 Cf.: "Every effect that God is able to produce by the mediation of a secondary cause he is able to produce immediately by himself. But he is able to produce an intuitive cognition of a corporeal thing by the mediation of a [corporeal] object. Therefore, he is able to produce this cognition immediately by himself"; "Omnem effectum quem potest Deus mediante causa secunda potest immediate per se; sed in notitiam intuitivam corporalem potest mediante obiecto; ergo potest in eam immediate per se" (Quod. VI, q. 6, OTh IX, 604).

20 "si videam intuitive stellam exsistentem in caelo, illa visio intuitiva, sive sit sensitiva sive intellectiva, distinguitur 
object A (but not the intuitive cognition of A), A ceases to exist, and the intuitive cognition of A thus becomes an intuitive cognition of a non-existent object. ${ }^{21}$

We have seen in the previous section that a (naturally caused) intuitive cognition of an object can cause an evident cognition of a contingent proposition regarding that object, for example the proposition that the object exists (cf. Scheme 1). Divinely caused intuitive cognitions of nonexistent objects can also cause evident cognitions of contingent propositions regarding those objects: "if God causes in me an intuitive cognition of a non-existent object and conserves this cognition in me, I can, through this cognition, judge that the thing does not exist". ${ }^{22}$

Taking into consideration that an intuitive cognition of a certain object, whether it is caused naturally or supernaturally, causes an abstractive cognition of that same object, Ockham's theory of supernaturally caused intuitive and abstractive cognition can be summarized as in Scheme 2 (brackets indicate non-existence).

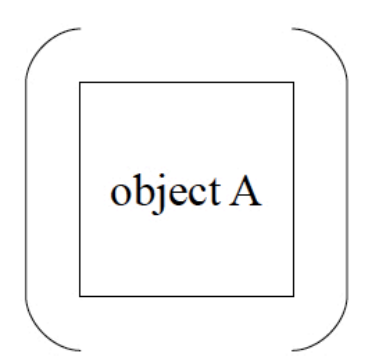

Scheme 2

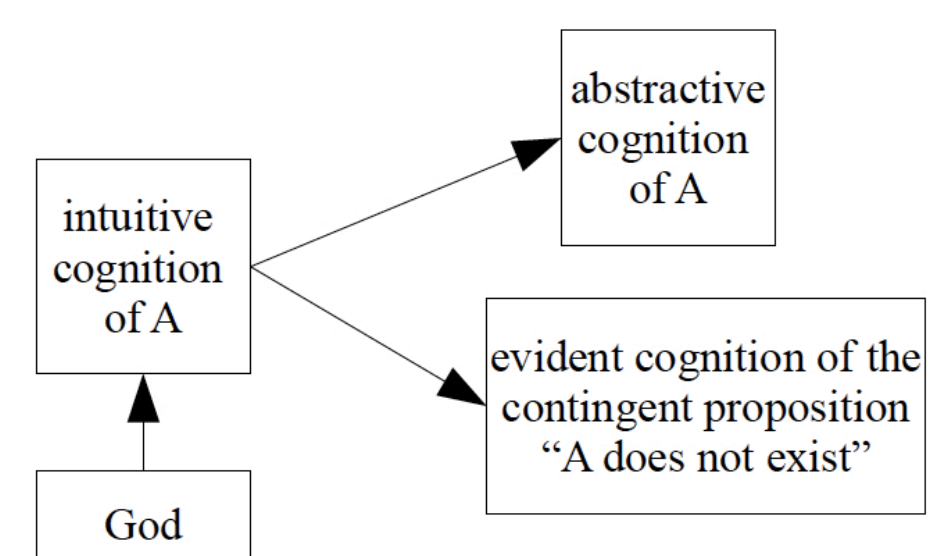

God

Considering both naturally and supernaturally caused intuitive cognitions, it should be clear that "intuitive [cognition] is that by which one knows that a thing exists when it exists, and that it does not exist, when it does not exist". ${ }^{23}$ (i) when the intuitive cognition of an object A is caused naturally, then A certainly exists (cf. supra), and the intuitive cognition of A can cause an evident cognition of the (true) proposition "A exists"; (ii) when the intuitive cognition of A is caused supernaturally, in the absence of $\mathrm{A}$, then it can cause an evident cognition of the (true) proposition "A does not exist". In the second case, the evident cognition of the proposition "A does not exist" is caused by an intuitive cognition (of A) which is itself caused supernaturally; hence this cognition of the proposition "A does not exist" is (indirectly) caused supernaturally as well. Ockham emphasizes that an intuitive cognition of a "negative' proposition (i.e. one of the form "A does not exist") is possible only if that cognition is supernatural: "I can judge through intuitive cognition that a thing does not exist when it does not. But this cognition cannot be natural". ${ }^{24}$

There seems to remain one problem, however. We saw that Ockham provides two proofs for the thesis that one can have intuitive cognitions of non-existent objects. The intuition behind both of

loco et subiecto ab obiecto viso; igitur ista visio potest manere stella destructa" (Ord. Prol., q. 1, OTh I, 39). The same example is used in (Quod. VI, q. 6, OTh IX, 605).

21 After the object A has ceased to exist, the cognizer can no longer be in any causal relationship with it. Still, Ockham emphasizes, the cognizer can continue to have an intuitive cognition of that object. This shows that causal contact with $\mathrm{A}$ is not a necessary condition to have an intuitive cognition of $\mathrm{A}$. The implications of this claim in the debate whether Ockham's epistemology is internalist or externalist are discussed in Brower-Toland (2007).

22 "si Deus causet in me cognitionem intuitivam de aliquo obiecto non exsistente et conservet illam cognitionem in me, possum ego mediante illa cognitione iudicare rem non esse" (Rep., q. 12-13, OTh V, 260).

23 "[cognitio] intuitiva est illa mediante qua cognoscitur res esse quando est, et non esse quando non est" (Rep., q. 1213, OTh V, 256).

24 "per cognitionem intuitivam possum iudicare rem non esse quando non est. Sed ista cognitio non potest esse naturalis" (Rep., q. 12-13, OTh V, 259). 
these proofs runs as follows: an intuitive cognition $\mathrm{C}$ of an object $\mathrm{A}$ is 'independent' of that object; therefore, it is possible that $\mathrm{C}$ exists while $\mathrm{A}$ does not. Thus, one and the same intuitive cognition, $\mathrm{C}$, can cause evident cognition of both the proposition that $\mathrm{A}$ exists (when $\mathrm{C}$ is naturally caused by $\mathrm{A})$ and the proposition that $\mathrm{A}$ does not exist (when $\mathrm{A}$ does not exist, and $\mathrm{C}$ is supernaturally caused by God directly). Boehner calls this "the somewhat embarrassing situation, that by the same intuitive knowledge sometimes existence is evidently affirmed, and sometimes non-existence evidently affirmed" (Boehner 1943, 231). Ockham answers that "it is not a problem for one cause, together with another partial cause, to cause an effect, while this [cause] alone, without the other partial cause, causes the opposite effect". ${ }^{25}$ Thus, when C is caused naturally (by A), then A and C are partial causes that together cause an evident cognition of the proposition "A exists"; but when C is caused supernaturally (by God), then $\mathrm{C}$ alone (without A) causes an evident cognition of the opposite proposition "A does not exist". ${ }^{26}$

\section{The Core of the Boehner/Karger Debate: Two Conflicting Interpretations}

Equipped with this overview of Ockham's theory of intuitive and abstractive cognition, we are now in a position to examine the Boehner/Karger debate. At the core of this debate are two conflicting interpretations of one of Ockham's texts. In this section, I will discuss this text and Boehner's and Karger's interpretations of it.

In the previous section we saw that, according to Ockham, it is possible to have a (supernaturally caused) intuitive cognition of a non-existent object A. This intuitive cognition will cause an evident cognition of the proposition "A does not exist" (cf. Scheme 2). Walter Chatton, one of Ockham's most gifted critics, objected to this position, because it (supposedly) entails that God cannot cause in us a cognition which causes us to judge that a non-existent thing exists (which he should be able to do, because it does not involve a contradiction). ${ }^{27}$ Chatton reasons as follows. (I) A cognition which would cause us to judge that a non-existent thing exists, has to be either intuitive or abstractive. (II) It cannot be intuitive, because an intuitive cognition of a non-existent thing cannot cause us to judge that that thing exists (it can only cause us to judge that that thing does not exist; cf. supra). (III) But neither can it be abstractive, since abstractive cognitions cannot cause cognitions of contingent propositions, such as "this object exists" or "this object does not exist" (cf. Section 2). (IV) Therefore, such a cognition (i.e. a cognition which causes us to judge that a nonexistent thing exists) cannot exist at all and hence, God cannot cause it in us. However, as I already mentioned, it does not involve a contradiction for God to cause such a cognition in us, and therefore, he should be able to do it. ${ }^{28}$

Ockham replies to this objection, and it is exactly this reply which is interpreted in two conflicting ways by Boehner and Karger. Ockham's reply reads as follows:

God can cause a belief-act through which I believe a thing to be present that is [in fact] absent [i.e. through which I believe a non-existent thing to exist;] this belief-cognition will

25 "non est inconveniens quod aliqua causa cum alia causa partiali causet aliquem effectum et tamen quod illa sola sine alia causa partiali causet oppositum effectum" (Ord. Prol., q. 1, OTh I, 71).

26 Cf. also: "although it is problematic for one and the same cognition to be the total cause of one judgment and its contrary [...], it is, however, not problematic that [this cognition] is the partial cause of one judgment when the object exists, and similarly, the partial cause of the contrary judgment when the object does not exist"; "quia licet sit inconveniens quod eadem notitia sit causa totalis unius iudicii et iudicii contrarii [...], tamen non est inconveniens quod sit causa partialis unius iudicii quando res existit, et similiter causa partialis iudicii contrarii quando res non existit" (Quod. V, q. 5, OTh IX, 496).

27 Chatton did not talk about (non-)existent objects, but about present/absent objects. In this paper, however, I follow Karger, according to whom "it makes no difference to [Chatton's] argument or to Ockham's response to it if one substitutes one set of notions [existent/non-existent] for the other [present/absent]" (Karger 1999, 224).

28 For Ockham's own presentation of Chatton's argument, see (Quod. V, q. 5, OTh IX, 496). 
be abstractive, not intuitive. And through such an act of faith a thing can appear to be present when it is [in fact] absent [i.e. a non-existent thing can appear to exist]; but this cannot happen through an evident act $[. .$.$] because 'evident cognition' implies that things$ are in reality just as is indicated by the proposition to which assent is given. ${ }^{29}$

It is important to note that although Ockham states that God can cause a belief-act about a nonexistent object A, he remains completely silent about whether this belief-act is caused directly or indirectly (i.e. via a non-complex cognition of A). We will see below that some of the interpretations of Ockham's reply take this causation to be direct, while others take it to be indirect.

This is a crucial difference, since Chatton's challenge is that God should be able to cause in us a non-complex cognition of A which then itself causes the belief that A exists; in other words, God should be able to cause indirectly the belief that A exists. Hence, if Ockham's reply is that God is able to cause directly the belief that A exists, then there is a clear mismatch between Chatton's objection on the one hand and Ockham's reply on the other (Chatton claims that indirect causation should be possible; Ockham's reply shows that direct causation is possible according to his theory). One explanation for this mismatch is that Ockham has squarely missed the point of Chatton's objection. Another, more plausible (and more charitable) explanation is that Ockham denies Chatton's basic assumption that God is able to cause in us a non-complex cognition which causes us to judge that a non-existent thing exists. In this case, it would be no problem if Ockham's theory entails that God does not have this ability. However, this would be a dangerous move, since this ability does not seem to involve any contradiction (as is emphasized by Chatton), and thus God should be able to have and exercise it. These troubling aspects of the 'direct causation'-reading should be contrasted with the alternative reading, according to which Ockham's reply is that God is able to cause indirectly the belief that A exists: in the latter case, Ockham's reply adequately and successfully deals with Chatton's objection (Chatton claims that indirect causation should be possible; Ockham's reply acknowledges this claim, and shows that indirect causation is indeed possible according to his theory). ${ }^{30}$

We now turn to Boehner's interpretation of Ockham's reply. He writes: “God [...] cannot cause such an evident cognition. He can, however, cause a [non-evident] act of belief [...] The cognitive basis for this [non-evident] belief cannot be the notitia intuitiva, but only a notitia abstractiva" (Boehner 1943, 232, his emphasis). According to Boehner, Ockham thus says that God cannot cause in us an evident cognition of the proposition "this object exists" when it does not exist, because that would imply a contradiction: evident cognition is (by definition) only possible of true propositions, so if an object A does not exist, then the proposition "A exists" is false, and hence it is impossible to have an evident cognition of it. However, God can cause in us a non-evident belief regarding this proposition.

Because the non-evident belief that A exists is caused immediately by God, it is not necessary to assume that it is also caused by a non-complex cognition of the object A. Boehner, however, does assume that there is a non-complex cognition of $\mathrm{A}$, which acts as the cognitive basis for the nonevident belief that A exists. Boehner emphasizes that this non-complex cognition has to be abstractive: if it were intuitive, then the belief based on it would be evident instead of non-evident.

It is not very clear what Boehner exactly has in mind with the notion of 'cognitive basis'. He does not seem to be using it as a mere synonym for 'cause', because each time he wants to talk about a causal relation, he meticulously uses the word 'cause' itself (for example: "God could deceive us by this supernaturally caused or conserved intuitive knowledge", "it is impossible for

29 "Deus potest causare actum creditivum per quem credo rem esse praesentem quae est absens. Et dico quod illa cognitio creditiva erit abstractiva, non intuitiva; et per talem actum fidei potest apparere res esse praesens quando est absens, non tamen per actum evidentem [...] nam cognitio evidens importat quod ita sit in re sicut denotatur per propositionem cui fit assensus" (Quod. V, q. 5, OTh IX, 498).

30 Thanks to an anonymous referee for some very helpful discussions about this point. 
God to cause in us such a cognition", "God, therefore, cannot cause such an evident cognition", Boehner 1943, 232, my emphases). One plausible interpretation is that the cognitive basis of a belief is related to the compositionality (modularity) of understanding. Believing, and thus understanding, a complex proposition like " $\mathrm{A}$ is $\mathrm{B}$ " requires one to have at least a minimal understanding of the proposition's non-complex constituents, 'A' and 'B' (for example, if one does not understand what 'white' means, then one can impossibly understand the proposition "Socrates is white"). These (non-complex) cognitions of the proposition's constituents do not cause a (complex) cognition of the proposition itself; but because they are necessary conditions for the cognizer to be able to have this complex cognition, they are said to constitute its cognitive basis. This interpretation is supported by Ockham's theory of judgment, according to which "every act of judgment presupposes [...] a non-complex cognition of its terms, because it presupposes an act of apprehension, and an act of apprehending a proposition presupposes a non-complex cognition of its [i.e. of that proposition's] terms". 31

Furthermore, recalling Section 2 (especially Footnotes 10 and 11), it should be noted that the relation of cognitive basis does not strictly exclude causality: if one has intuitive cognitions of Socrates and his whiteness, then these non-complex cognitions can cause an evident complex cognition of the proposition "Socrates is white", while also being its cognitive basis. However, in the case discussed by Boehner, the non-complex cognition of $\mathrm{A}$ is abstractive instead of intuitive, and the complex cognition of the proposition "A exists" is non-evident instead of evident, so this does not seem to be a case where cognitive basis and causality coincide. In summary, Boehner's notion of 'cognitive basis' does not seem to be a causal notion in general, and certainly not in the case he explicitly discusses. ${ }^{32}$

Let us now reconsider the abstractive, non-complex cognition of A that serves as the cognitive basis for the non-evident belief that A exists. This has to be caused by something (otherwise, it would not have come into existence). Naturally speaking, however, an abstractive cognition of an object A can only be caused by an intuitive cognition of A. Since A does not exist (ex hypothesi), there can be no (naturally caused) intuitive cognition of $A$, and hence, there can be no natural cause for the abstractive cognition of $\mathrm{A}$. Therefore, the abstractive cognition of $\mathrm{A}$ has to be caused directly by God (just like the belief of which it is the cognitive basis).

Scheme 3 summarizes Boehner's interpretation of Ockham's reply (as before, the two unlabeled arrows represent causal relationships; however, there is now also one arrow labeled 'bases', where ' $\mathrm{X}$ - bases $\rightarrow \mathrm{Y}$ ' is to be read as ' $\mathrm{X}$ is the cognitive basis of $\mathrm{Y}$ ').

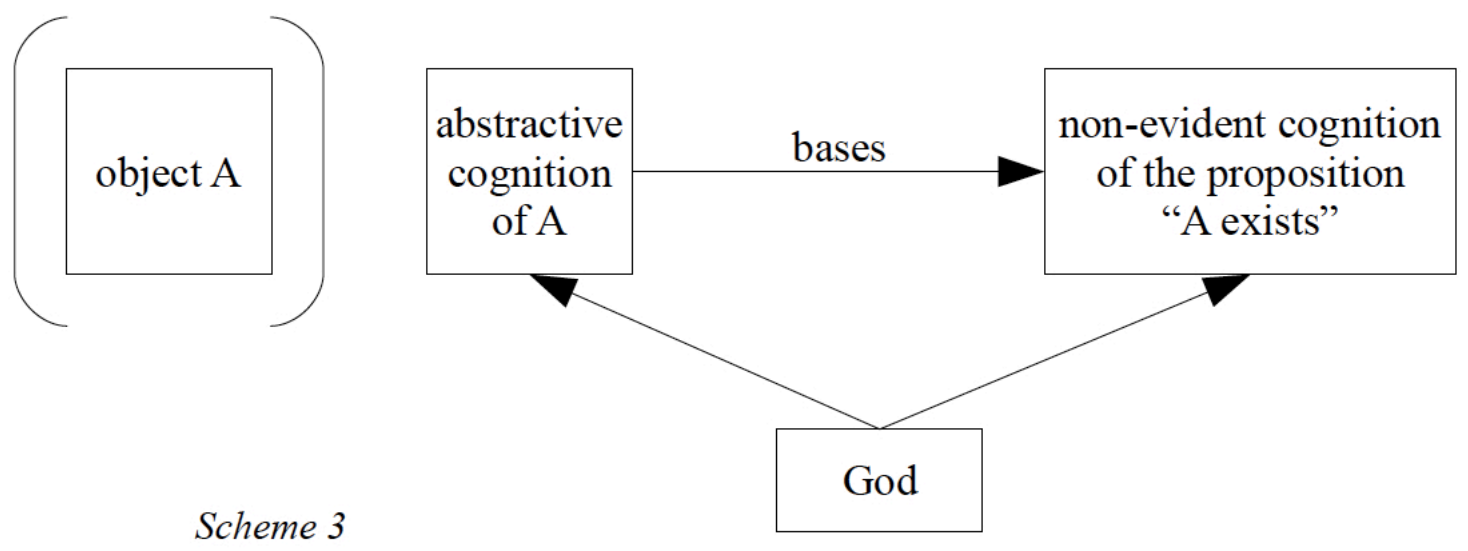

Before examining Karger's own interpretation of Ockham's reply, we should look at her

31 "omnis actus iudicativus praesupponit [...] notitiam incomplexam terminorum, quia praesupponit actum apprehensivum. Et actus apprehensivus respectu alicuius complexi praesupponit notitiam incomplexam terminorum" (Ord. Prol., q. 1, OTh I, 21).

32 Thanks to an anonymous referee for some very helpful discussions about this point. 
reconstruction of Boehner's interpretation. Karger summarizes Boehner's interpretation as follows: "Boehner took Ockham [...] to have conceded [...] that it is possible for God to cause us to judge a nonexistent thing to exist by causing in us a cognition of that thing which, in turn, would cause the false judgment [...] he thought that Ockham's response to Chatton consisted in denying that that cognition would be intuitive and in asserting instead that it would be abstractive" (Karger 1999, 214, Karger's emphasis). Karger seems to misrepresent Boehner's interpretation. Boehner himself says that God causes in us directly the false belief; the abstractive cognition (which is also caused directly by God) is not said to be this belief's cause, but rather to be its "cognitive basis" (Boehner 1943, 232). According to Karger, however, Boehner says that God causes in us (only) the abstractive cognition, which then, on its own, causes the false judgment. Finally, note that Karger remains completely silent about the question whether this false judgment is an evident or a nonevident (complex) cognition.

Scheme 4 summarizes Karger's (mis)representation of Boehner's interpretation. As I discussed, there are three differences with the previous scheme: (i) there is no causal arrow from 'God' to 'cognition of the proposition "A exists", (ii) the relationship between 'abstractive cognition of A' and "cognition of the proposition "A exists" is no longer one of cognitive basis, but a causal one, and (iii) the assent to the proposition "A exists" is no longer claimed to be non-evident.

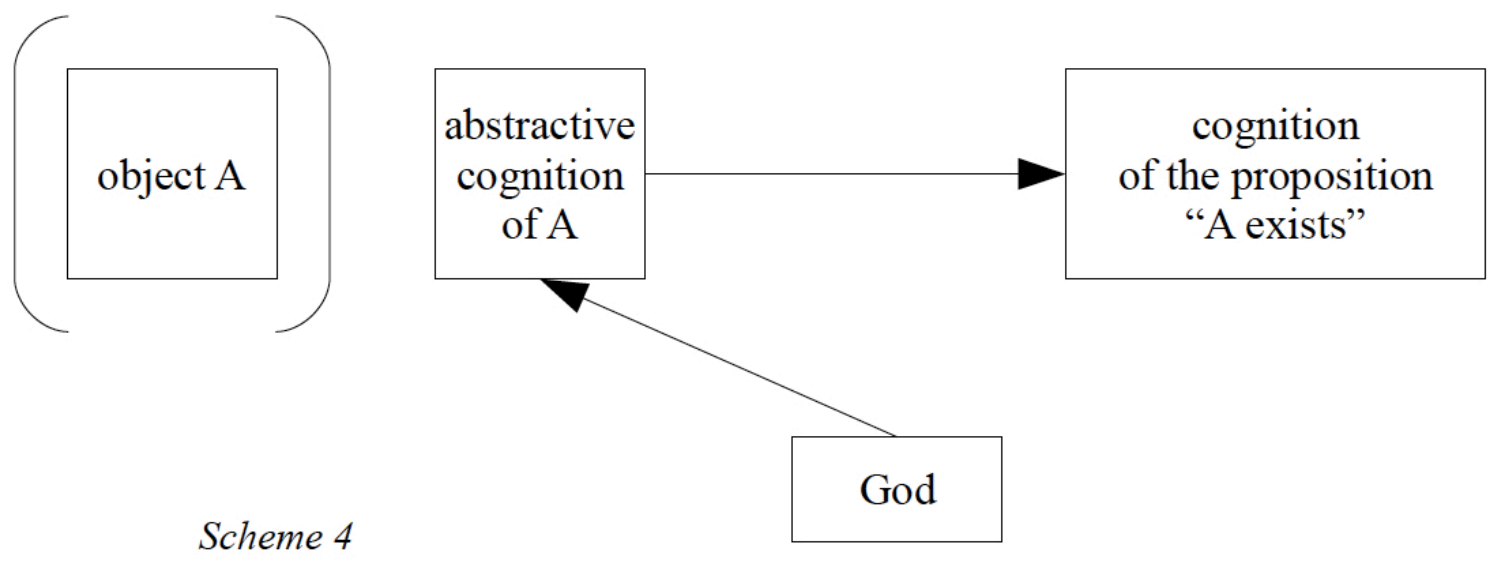

Karger claims that Boehner takes the cognition of the non-existent object A to be abstractive. This aspect of Karger's reconstruction of Boehner's interpretation is correct: Boehner indeed thought that the cognition of A - whether it is the cause of the false judgment (as in Karger's summary of Boehner; cf. Scheme 4) or only its 'cognitive basis' (as Boehner himself says; cf. Scheme 3) - has to be abstractive, rather than intuitive; cf. the quotation already given above: "The cognitive basis for this belief cannot be the notitia intuitiva, but only a notitia abstractiva" (Boehner 1943, 232, his emphasis).

We now focus on Karger's own interpretation of Ockham's reply to Chatton. According to Karger, Ockham says that God can make us judge a non-existent thing to exist by "causing directly in us the very act of judgment itself" (Karger 1999, 212). Ockham himself says that "this beliefcognition will be abstractive, not intuitive"; ${ }^{33}$ here, he is using the term 'abstractive cognition' in its broad sense (cf. Footnote 4 and the end of Section 2), according to which all complex cognitions of propositions are called abstractive (Karger 1999, 212).

Karger states that if this were Ockham's entire reply to Chatton, it would not be very successful: Chatton stated that it is possible for God to cause in us a non-complex cognition which causes us to make a false judgment (while Ockham's theory purportedly does not allow for that possibility). ${ }^{34}$

33 "illa cognitio creditiva erit abstractiva, non intuitiva" (Quod. V, q. 5, OTh IX, 498).

34 It is clear that Chatton really has a non-complex cognition in mind, because of the argument he gives for his view. To prove that the cognition under consideration cannot exist on Ockham's view, Chatton supposes that it does exist, says that it would have to be either intuitive or abstractive, then deduces a contradiction for both possibilities, and 
However, all Ockham has shown so far is that God can cause in us directly a complex cognition of a false proposition (a false belief), while saying nothing about any non-complex cognition. Put differently, the only thing Ockham has shown is that "God [can] cause in us directly the very act by which we judge the nonexistent thing to exist, an act that is not a cause of the judgment but the judgment itself" (Karger 1999, 213). Thus far, Ockham's reply seems to be missing the point of Chatton's attack.

However, since God has caused the (false) judgment about the non-existing thing directly and alone (without any secondary cause), Karger claims that "the cognition we are having of the thing plays no part at all in causing the judgment [and hence] may well be intuitive (though it need not be)" (Karger 1999, 213). God can cause in us both a non-complex cognition of the non-existent object A and a false belief that A exists. If the non-complex cognition of A is abstractive, God's work is done; if it is intuitive, God also has to block this intuitive cognition from causing evident assent to the proposition "this object does not exist". So it is "possible that God should first cause in us an intuitive cognition of a nonexistent thing, that he should next prevent that cognition from exercising its natural capacity of causing us to judge the thing not to exist, and that he should finally cause in us instead an erroneous act of judgment by which we judge the thing to exist" (Karger 1999, 213). ${ }^{35}$

Karger's interpretation of Ockham's reply to Chatton can be represented by Schemes 5 and 6 . Scheme 5 represents the 'intuitive cognition'-case (the black bar represents God's blocking of the intuitive cognition of A causing evident cognition of the proposition "A does not exist"); Scheme 6 represents the 'abstractive cognition'-case.

Again, note that in both Schemes 5 and 6, nothing is claimed about the (complex) cognition of the proposition "A exists" being evident or non-evident. The cognition of "A does not exist" in Scheme 5 is claimed to be evident, since it is (would be) caused by an intuitive cognition of A; however, this cognition does not exist, because God supernaturally blocks the intuitive cognition from causing it.
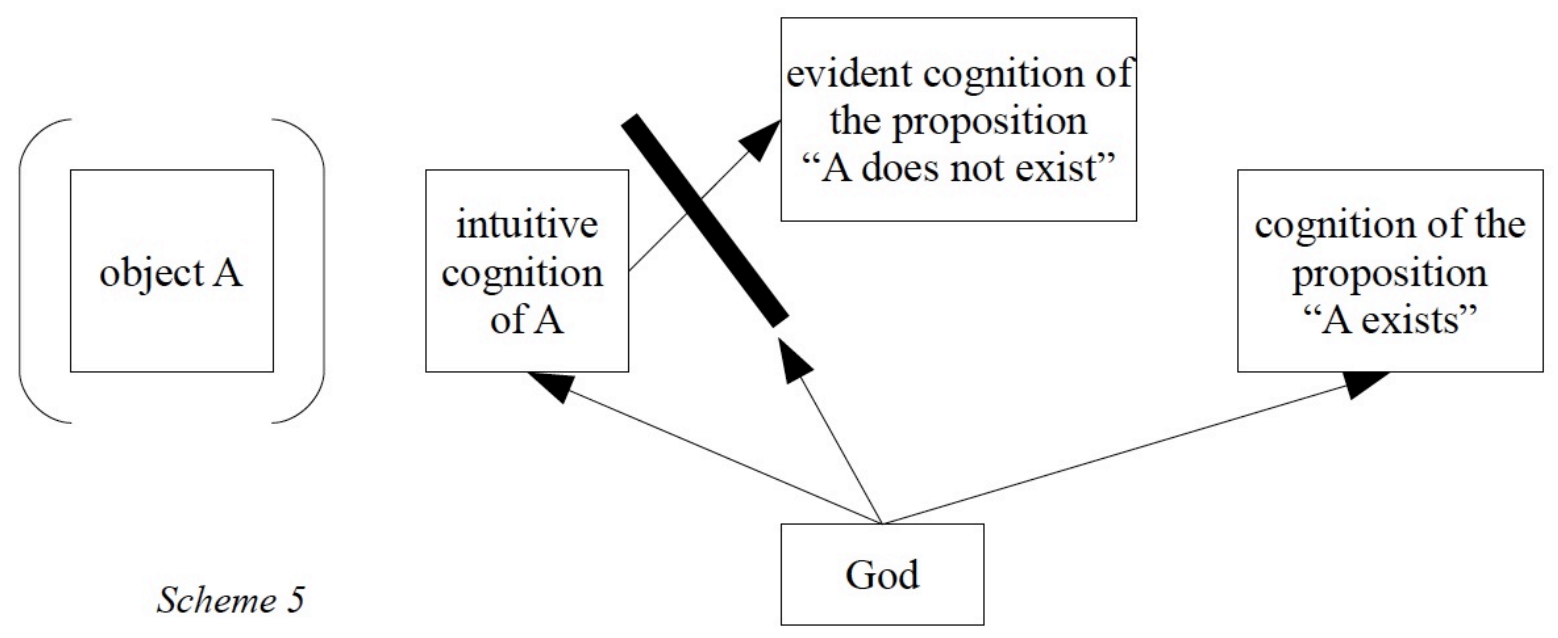

finally concludes that it cannot exist after all (cf. the structure (I) - (II) - (III) - (IV) in my presentation of Chatton's argument). We already saw in Section 2 that the distinction of intuitive vs. abstractive cognitions is a distinction within the realm of non-complex cognitions. (At least according to the most widespread interpretation of this distinction. There is of course the alternative interpretation, mentioned in Footnote 4 and at the end of Section 2, according to which all complex cognitions are abstractive as well. It is, however, very implausible that Chatton has this alternative interpretation in mind here.) Hence, Chatton uses in his argument a distinction which applies only to non-complex cognitions. Therefore, for his argument to make sense, it is necessary that the cognition under consideration is indeed non-complex.

35 I assume that the words 'first', 'next' and 'finally' in Karger's description are not meant to indicate any temporal order in God's acts, but merely serve to enumerate them. 


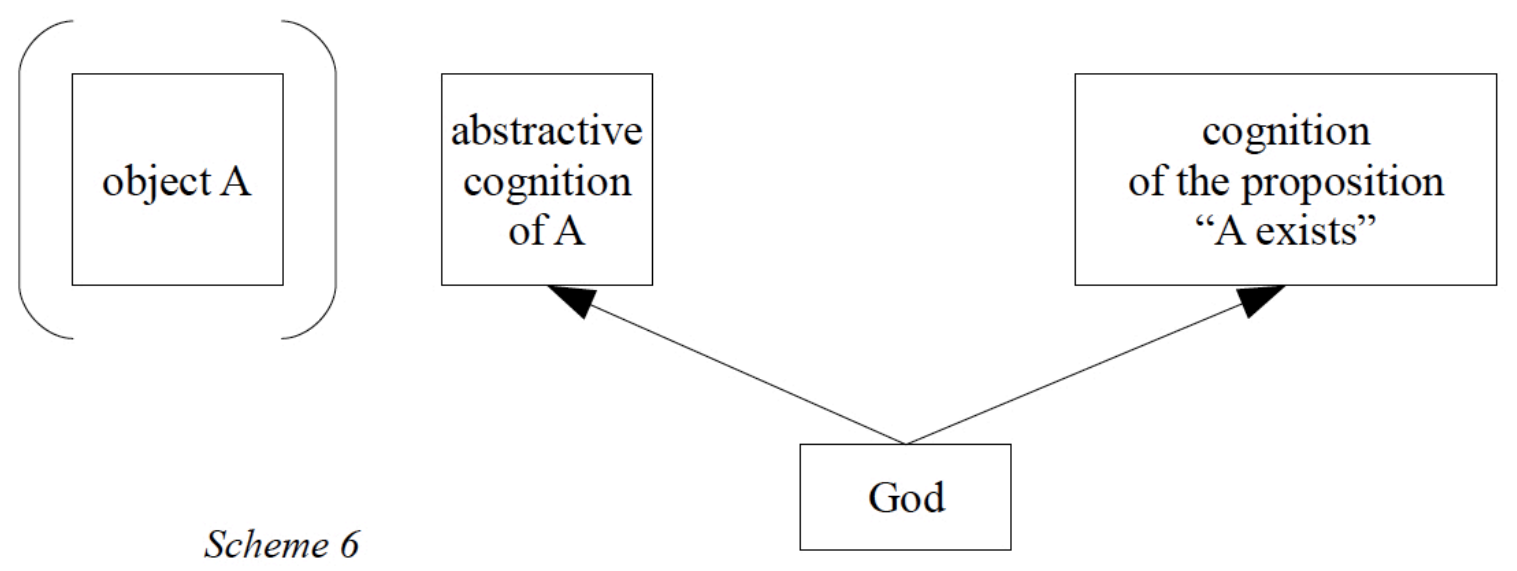

\section{The (In)fallibility of Intuitive Cognition}

We have seen that Chatton's objection is that it should be possible for God to cause in us a (noncomplex) cognition of a non-existent thing that causes us to judge falsely that that thing exists (whereas Ockham's theory supposedly does not allow for this possibility). To give a satisfactory answer to Chatton, it therefore does not suffice for Ockham to explain that God can cause in us a false judgment directly; rather, he really needs to explain how God can cause in us a non-complex cognition of a non-existent thing, which then, by itself (i.e. without any further divine causal interference), causes the false judgment. On Karger's interpretation, Ockham's reply is no real answer to Chatton: the false judgment is caused (directly and solely) by God himself ${ }^{36}$ and thus not by the non-complex cognition, whether it is intuitive or abstractive (cf. Schemes 5 and 6, respectively). On Boehner's interpretation, Ockham's reply is not an adequate answer to Chatton either, but it does seem to be closer to being one: the false (non-evident) judgment is still caused directly by God, but God also causes an (abstractive) non-complex cognition which serves as the cognitive basis for that false judgment (cf. Scheme 3).

Thus, neither on Karger's nor on Boehner's interpretation is Ockham's reply to Chatton completely successful. On neither interpretation is Chatton's objection (can God cause in us a noncomplex cognition which itself causes a false judgment?) truly answered: both interpretations involve a false judgment that is caused directly by God, not by any non-complex cognition (which is itself caused by God). However, on Karger's misrepresentation of Boehner's interpretation (cf. Scheme 4), Ockham does give a real answer to Chatton's question: God causes in us a non-complex (abstractive) cognition which itself (without God) causes a false judgment. This false judgment is thus caused by God only indirectly (via the non-complex abstractive cognition), which is perfectly consistent with Ockham's own writings: although he states that God causes the false judgment, he nowhere claims that God does this directly (as I have argued above, if he were to make the latter claim, his reply to Chatton would be unsuccessful).

One problem seems to remain for this interpretation. It says that an abstractive cognition causes a cognition of the contingent proposition "this object exists". We already saw that Ockham's general theory of intuitive and abstractive cognitions does not allow for this: abstractive cognitions cannot

36 As is explicitly acknowledged by Karger: "the cognition we are having of the thing plays no part at all in causing the judgment, the sole cause of which is God himself” (Karger 1999, 213). Karger's emphasis on the judgment being caused directly by God seems strange, given that she allows that abstractive cognitions can indeed cause judgments - just no evident judgments about contingent propositions (Karger 1999, 216). 
cause cognitions of contingent propositions. Chatton himself points this out as well: it is exactly part (III) of (our reconstruction of) his argument (cf. supra).

However, what Ockham actually says is that "through abstractive cognition no contingent truth [...] can be evidently known" (my emphasis) ${ }^{37}$ abstractive cognitions cannot cause an evident cognition of a contingent proposition; thus, Ockham remains silent about the possibility of an abstractive cognition causing a non-evident cognition of a contingent proposition. Furthermore, in his reply to Chatton, Ockham emphasizes that the complex cognition of the false proposition "this object exists" cannot be evident: "through such an act of faith a thing can appear to be present when it is [in fact] absent [i.e.: a non-existent thing can appear to exist]; but this cannot happen through an evident act" (my emphasis). ${ }^{38}$ Therefore, Ockham can consistently maintain that the false judgment under consideration is (i) non-evident and (ii) caused by an abstractive cognition. (Karger, too, maintains that on Ockham's theory, abstractive cognitions can cause non-evident judgments; cf. the second part of Footnote 36.)

From a general logical perspective, this means that Ockham replies to Chatton's argument by rejecting step (III) of it, viz. the thesis that abstractive cognitions cannot cause cognitions of contingent propositions. Ockham only endorses the modified thesis - let's call it (III') - that abstractive cognitions cannot cause evident cognition of contingent propositions, which is strictly weaker than thesis (III): thesis (III) entails thesis (III'), but not vice versa. Hence, if one is committed to thesis (III), then one should (rationally) also be committed to thesis (III'); however, if one is committed to thesis (III'), then one is not rationally obliged to accept (III) as well. It is thus perfectly rational for Ockham to accept thesis (III'), while rejecting thesis (III).

I already showed that neither on Karger's nor on Boehner's interpretation is Ockham's reply to Chatton completely successful. I have now argued for a third interpretation, according to which his reply is successful, and which clearly pinpoints the mistake in Chatton's argument (step (III)). Adopting a principle of charity and preferring the interpretation on which Ockham's reply is most successful, it should be concluded that the third interpretation is superior to both Boehner's and Karger's interpretation.

The third interpretation of Ockham's reply to Chatton is represented in Scheme 7.

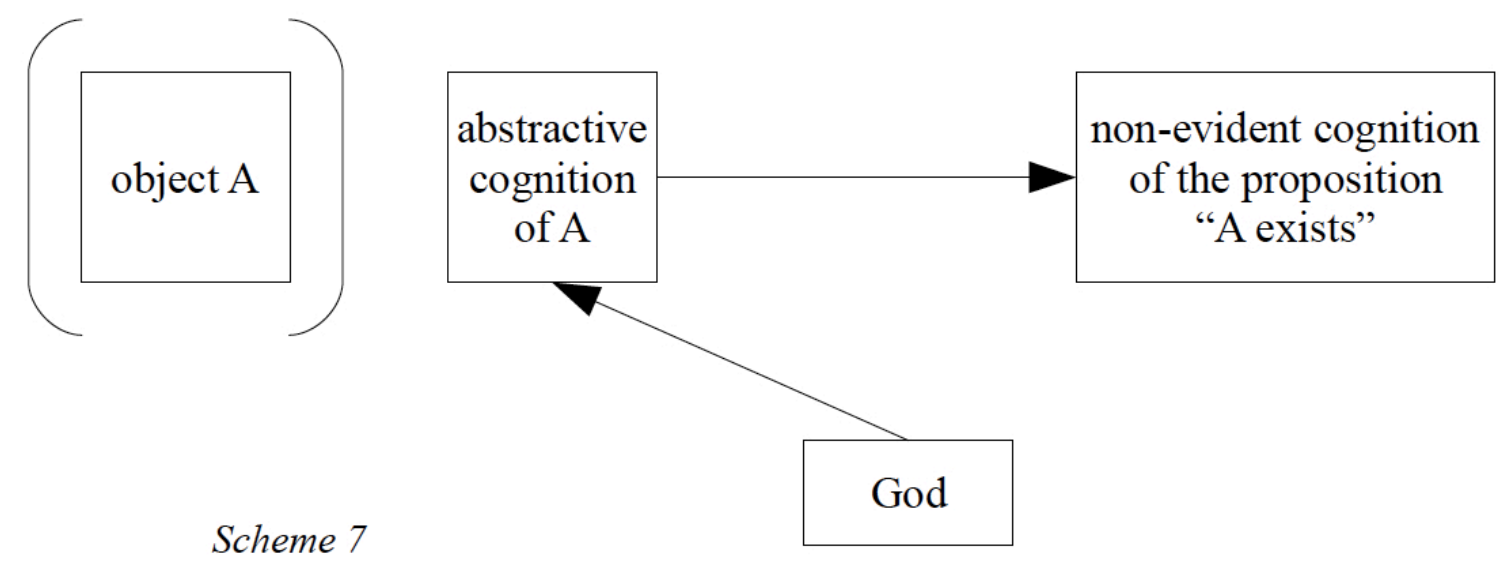

On the one hand, this scheme only differs from Karger's misrepresentation of Boehner's interpretation (cf. Scheme 4) in that it explicitly says that the assent to the proposition "A exists" is non-evident; on the other hand, it only differs from Boehner's interpretation itself (cf. Scheme 3) in that it leaves out the causal arrow from 'God' to 'non-evident cognition of the proposition "A

37 "per notitiam abstractivam nulla veritas contingens, maxime de praesenti, potest evidenter cognosci" (Ord. Prol., q. 1, OTh I, 32).

38 "per talem actum fidei potest apparere res esse praesens quando est absens, non tamen per actum evidentem" (Quod. V, q. 5, OTh IX, 498). 
exists"' and replaces the 'cognitive basis'-arrow with a causal arrow. In any case, it turns out that Boehner's interpretation (Scheme 3/Scheme 4) is much closer to the third interpretation (Scheme 7) than Karger's interpretation (Schemes 5 and 6). Since I have argued this third interpretation to be the correct one, this means that Boehner's interpretation is much closer to being correct than Karger's. In other words, Boehner's interpretation is superior to that of Karger.

Neither on Boehner's interpretation of Ockham's reply to Chatton (Scheme 3) nor on Karger's misrepresentation of it (Scheme 4) does an intuitive cognition co-occur with a false judgment. However, on Karger's own interpretation (Scheme 5 in particular), an intuitive cognition does cooccur with a false judgment, and is thus fallible. Karger, taking her own interpretation to be correct, views this as a definitive argument against the infallibility of intuitive cognition in Ockham: Boehner's claim that Ockham thought intuitive cognition to be infallible is solely based on (what Karger takes to be) his misinterpretation. She writes, for example: "On the basis of this misunderstanding of Ockham's reply to Chatton, Boehner [...] inferred that, on Ockham's doctrine, intuitive cognitions are infallible" (Karger 1999, 214, my emphasis).

I have just argued, however, that Boehner's interpretation is superior to that of Karger. I will now examine the consequences of this interpretation issue regarding the (in)fallibility of intuitive cognition. To this end, we need to distinguish between two senses of infallibility: a weak one and a strong one. An intuitive cognition will be called strongly infallible if it cannot co-occur with false judgments; it will be called weakly infallible if it cannot cause false judgments. The justification for this terminology is that causality obviously implies co-occurrence (if X causes $\mathrm{Y}$, then $\mathrm{X}$ and $\mathrm{Y}$ cooccur); reasoning contrapositively, it follows that if an intuitive cognition cannot co-occur with a false judgment, then it cannot cause a false judgment either. In other words, strong infallibility entails weak infallibility (but not vice versa).

On the basis of his interpretation of Ockham's reply to Chatton, Boehner infers that intuitive cognition is infallible: not even God can cause in us an intuitive cognition that would cause a false judgment; ${ }^{39}$ therefore, such intuitive cognitions do not exist. (This is also compatible with our third interpretation, which says that it is an abstractive, rather than an intuitive, cognition which causes the false judgment.) It should be clear that Boehner is talking about weak infallibility here: intuitive cognition cannot cause false judgments. "[E]very assent which is based on perfect intuition knowledge [...] is infallibly true" (Boehner 1943, 231-232). It is probably also this weak sense of infallibility that Ockham himself has in mind when stating that "intuitive cognition in no way leads the intellect to error", 40 because 'leading' ('ponere') is an 'active' verb, which is more likely to express a relation of causality rather than one of mere co-occurrence.

It is thus clear that according to Ockham's theory, intuitive cognition is weakly infallible. One legitimate question remains, however: is it also strongly infallible? At this point, Karger's interpretation becomes important again. Although I have argued that Karger's interpretation ultimately fails qua interpretation of Ockham's reply to Chatton, Ockham might nevertheless very well agree that Karger's description of the 'intuitive cognition'-case (Scheme 5) constitutes a genuine possibility (the fact that this scenario is metaphysically possible does not entail that it is also plausible in any way; cf. infra). In this scenario, the intuitive cognition of A, while not causing the false judgment that A exists, does co-occur with it. Thus, it is possible for an intuitive cognition to co-occur with a false judgment, which implies that intuitive cognition is not strongly infallible. ${ }^{41}$

Let's summarize. On the one hand, I have argued that intuitive cognition is weakly infallible: it

39 Cf. “on Ockham's view even God cannot cause an intuitive cognition that gives rise to a false judgment [...] God can cause a false belief directly in us, although this will not be a case in which the judgment is formed in virtue of an intuitive cognition" (Stump 1999, 187). Cf. also Schemes 3 and 4.

40 "notitia intuitiva [...] nullo modo ponit intellectum in errore" (Rep., q. 12-13, OTh V, 287).

41 Scheme 5 involves an intuitive cognition co-occurring with a false judgment, but it does not involve an intuitive cognition causing a false judgment. In our new terminology: Scheme 5 shows that intuitive cognition is not strongly infallible, but it does not show that intuitive cognition is not weakly infallible. 
cannot cause false judgments. On the other hand, it turned out that intuitive cognition is not strongly infallible: it can co-occur with false judgments. An important additional remark, however, is that in order to establish that intuitive cognition is not strongly infallible, rather heavy "miraclemachinery' was needed; cf. Karger: "In such a case [as represented in Scheme 5] God would have miraculously intervened three times [...] Though extraordinary, such a conjunction of miracles is possible" (Karger 1999, 213). ${ }^{42}$ This suggests that in almost all 'normal' situations, intuitive cognition will be not only weakly, but also strongly infallible.

\section{Conclusion}

In this paper, I have attempted to resolve the Boehner/Karger debate about the (in)fallibility of intuitive cognition in Ockham's epistemology. I first provided an extensive overview of Ockham's theory of (naturally and supernaturally caused) intuitive and abstractive cognitions, and then turned to the core of the Boehner/Karger debate, which has to do with an interpretation issue about one of Ockham's texts. I have showed that neither Boehner's nor Karger's interpretation is ultimately successful. I then proposed a third, new interpretation, and argued for its correctness. It turns out that this third interpretation is closely related with Boehner's interpretation, but not with that of Karger. Hence, Boehner's interpretation seems to be 'closer to being correct' than that of Karger. Finally, I proposed to distinguish between strong and weak senses of infallibility, and argued for three claims: (i) intuitive cognition is weakly infallible: it cannot cause false judgments; (ii) absolutely speaking, intuitive cognition is not strongly infallible: in certain, very abnormal, circumstances, it can co-occur with false judgments; (iii) in most 'normal' circumstances, however, intuitive cognition is not only weakly, but also strongly infallible.

These claims seem to have implications for Ockham's theory of knowledge more broadly speaking. For example, they seem to fit well with recent reliabilist and externalist interpretations of Ockham's epistemology (Panaccio and Piché 2009). Since intuitive cognition cannot cause false beliefs, and in 'normal' situations (which constitute the vast majority of all situations) cannot even co-occur with false beliefs, it certainly seems to have a 'tendency' to cause true beliefs.

In a 'normal' situation (without any divine interventions), a cognizer's beliefs are typically caused by intuitive cognitions, and are thus true (cf. Scheme 1). In a highly unlikely and far-fetched situation, however, her beliefs merely co-occur with intuitive cognitions, without being caused by them, and can thus be false (cf. Scheme 5). From an external perspective, this distinction between normal and far-fetched situations is perfectly clear. The cognizer herself, however, has no principled way to find out whether she is currently in a normal situation or in a far-fetched one, and hence, she cannot know whether her current beliefs are true or (possibly) false: she always has to take into consideration the possibility - however unlikely - that she is currently in a far-fetched situation à la Scheme 5. Hence, in all normal situations (which, again, constitute the vast majority of all situations), the cognizer's beliefs will be mainly true, but she will not know that her beliefs are mainly true. ${ }^{43}$

These suggestions show that the distinction between strong and weak infallibility has broader implications for Ockham's theory of knowledge. Of course, these suggestions are, for now, only tentative; their further exploration and systematic development will have to be left for future work.

42 Karger (2004) explores the skeptical consequences of such cases of 'divine deception'.

43 The dialectical role of far-fetched scenarios à la Scheme 5 in Ockham's theorizing thus seems to be similar to that of the 'fake barn' (and related) scenarios in contemporary epistemology (Goldman 1976). 


\section{Acknowledgments}

This paper was originally written for a master seminar at KU Leuven, taught by Russell Friedman. I would like to thank him for his very helpful comments and sustained encouragement to publish this paper. I would also like to thank Catarina Dutilh Novaes, Paul Vincent Spade and two anonymous referees for their helpful comments on earlier versions of this paper. Finally, I would like to thank Christoph Kelp for his help with translating the abstract from English to German.

\section{Bibliography}

Adams, M. 1987. William Ockham. Notre Dame: University of Notre Dame Press.

Boehner, P. 1943. The Notitia Intuitiva of Non-Existents According to William of Ockham. Traditio 1, 223-275.

Brower-Toland, S. 2007. Intuition, Externalism, and Direct Reference in Ockham. History of Philosophy Quarterly 24, 317-335.

Goldman, A. 1976. Discrimination and Perceptual Knowledge. Journal of Philosophy 73, 771-791.

Karger, E. 1999. Ockham's Misunderstood Theory of Intuitive and Abstractive Cognition. In: Spade, P. (ed.). The Cambridge Companion to Ockham. Cambridge: Cambridge University Press, 204-226.

Karger, E. 2004. Ockham and Wodeham on Divine Deception as a Skeptical Hypothesis. Vivarium 42, 225-236.

Ockham, W., 1967-1988. Opera Philosophica et Theologica, 17 volumes, Gál, G. et al. (eds.). St. Bonaventure: Franciscan Institute.

Panaccio, C. / Piché, D. 2009. Ockham's Reliabilism and the Intuition of Non-Existents. In: Lagerlund, H. (ed.). Rethinking the History of Skepticism: The Missing Medieval Background. Leiden: Brill, 97-118.

Stump, E. 1999. The Mechanisms of Cognition: Ockham on Mediating Species. In: Spade, P. (ed.). The Cambridge Companion to Ockham. Cambridge: Cambridge University Press, 168-203. 